\section{Commentary: Be ready to re-route your root replacement}

\author{
John Bozinovski, MD, MSc
}

In this issue of the Journal, Drs Fukunaga and Peterson report a case of an anomalous left circumflex coronary artery originating from the right coronary artery and coursing lateral and then posterior to the aorta, identified during planning for intervention on an aortic root aneurysm. ${ }^{1}$ They successfully replaced the aorta from the root to the innominate artery, sparing the valve with a root remodeling procedure without intervention on the anomalous coronary artery (ACA). Such anatomy and pathology occur often enough to be encountered a few times during a surgical career. Occasionally the preoperative investigation does not provide sufficient information to determine exactly what will be needed to fashion the repair. The ability to follow an alternative strategy is valuable to the operating surgeon. Central to this is an understanding of the risks of anomalous coronary arteries and their interventions, in addition to those associated with root surgery.

The operation performed was a remodeling valve-sparing root replacement (VSRR) that did not require an annuloplasty because of the presence of a nondilated annulus. Compared with a reimplantation VSRR, less dissection is required around the aortic annulus where the ACA was located. Had the annulus been dilated, other options could have been considered. These include an annular reinforcement procedure in addition to the remodeling VSRR, a reimplantation VSRR, or a composite valved conduit. To varying degrees, these all carry some risk to the left circumflex ACA. Mobilization of the ACA may be sufficient to

\footnotetext{
From the Division of Cardiac Surgery, The Ohio State University Wexner Medical Center, Columbus, Ohio.

Disclosures: The author reported no conflicts of interest.

The Journal policy requires editors and reviewers to disclose conflicts of interest and to decline handling or reviewing manuscripts for which they may have a conflict of interest. The editors and reviewers of this article have no conflicts of interest.

Received for publication Feb 9, 2021; revisions received Feb 9, 2021; accepted for publication Feb 18, 2021; available ahead of print Feb 26, 2021.

Address for reprints: John Bozinovski, MD, MSc, Division of Cardiac Surgery, The Ohio State University Wexner Medical Center, N816A Doan Hall, 410 West 10th Ave, Columbus, OH 43210 (E-mail: jovan.bozinovski@ osumc.edu).

JTCVS Techniques 2021;7:151-2

2666-2507

Copyright (C) 2021 The Authors. Published by Elsevier Inc. on behalf of The American Association for Thoracic Surgery. This is an open access article under the CC BY-NCND license (http://creativecommons.org/licenses/by-nc-nd/4.0/).

https://doi.org/10.1016/j.xjtc.2021.02.022
}

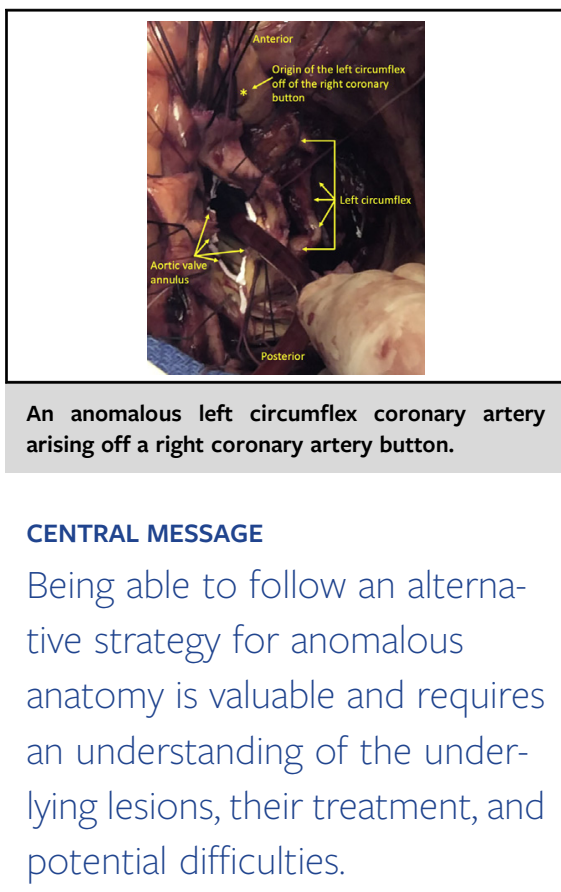

remove it from jeopardy, but in rare instances, relocation of the ACA or revascularization of the ACA may be necessary.

To decrease the diameter of the annulus, support it over time, and improve the coaptation height of the leaflets, the annular repair could have included a subannular stitch annuloplasty, an internal geometric ring annuloplasty, or an external annuloplasty. The former is used less often, likely because of concerns for durability. The internal geometric rings are newer innovations that show promise and do not require the same deep external aortic dissection needed in external ring annuloplasty. ${ }^{2}$ If an external annular procedure is being added to the remodeling procedure, a reimplantation procedure can be done instead, as it requires the same anatomic dissection. A valved conduit is another option, as it also does not require the same external dissection as the VSRR, thereby exposing the ACA to less jeopardy from kinking or direct injury. Furthermore, a valved conduit should not always be considered a lesser procedure. Evidence exists suggesting that the durable competency of an aortic valve-sparing procedure is impacted by the presence of a large indexed left ventricular end-systolic dimension. ${ }^{3}$ In a severely dilated left ventricle, a valved conduit may be a good choice.

ACAs are not all alike, and some are of greater concern than others. A left main coronary artery off a right sinus is more concerning for sudden death than a right coronary coming off a left sinus. ${ }^{4}$ An individual left circumflex 
coming off a right coronary artery is not as concerning; however, certain high-risk features, such as a slit-like ostium and a long intramural course, might require additional consideration for unroofing, relocation, or bypass. ${ }^{5}$ As was done in this case, often it only requires mobilization of the ACA, with care not to take annular bites too wide to kink the vessel or too deep to injure it.

\section{References}

1. Fukunaga N, Peterson M. Anomalous left circumflex artery: implications for valve-sparing root replacement. J Thorac Cardiovasc Surg Tech. 2021;7:146-8.
2. Mazzitelli D, Fischlein T, Rankin JS, Choi YH, Stamm C, Pfeiffer S, et al. Geometric ring annuloplasty as an adjunct to aortic valve repair: clinical investigation of the HAART 300 device. Eur J Cardiothorac Surg. 2016;49: 987-93.

3. Guo MH, Cole E, Fei LYN, Mussani J, Tran D, Glineur D, et al. Preoperative left ventricular end-systolic dimension predicts occurrence of aortic insufficiency following aortic valve-preservation and repair surgery. J Thorac Cardiovasc Surg. December 3, 2020 [Epub ahead of print].

4. Cheitlin MD, De Castro CM, McAllister HA. Sudden death as a complication of anomalous left coronary origin from the anterior sinus of Valsalva, a not-so-minor congential anomaly. Circulation. 1974;50:780-7.

5. Brothers JA, Frommelt MA, Jaquiss RDB, Myerburg RJ, Fraser CD Jr, Tweddell JS. Expert consensus guidelines: anomalous aortic origin of a coronary artery. J Thorac Cardiovasc Surg. 2017;153:1440-57. 